
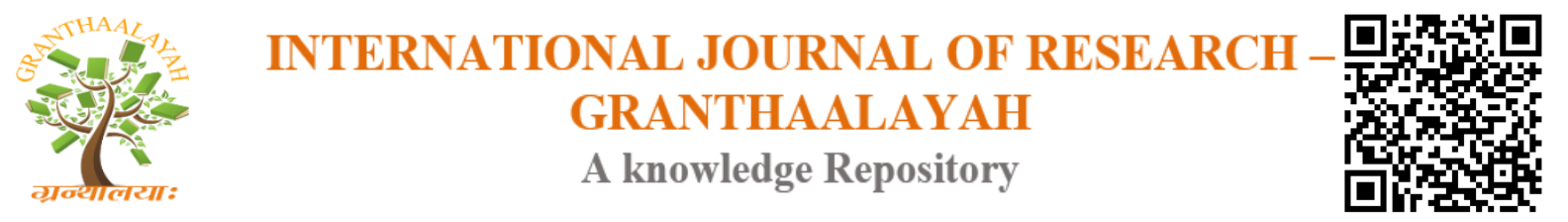

Social

\title{
COMMUNICATION SKILLS AS A KEY TO CAREER DEVELOPMENT IN THE DIGITAL AGE
}

\author{
Palle Manohar ${ }^{1}$, Dr. G. Chenna Reddy ${ }^{2}$ \\ ${ }^{1}$ Research Scholar, Department of English, Acharya Nagarjuna University, India \\ ${ }^{2}$ Assistant Professor, Department of English, Acharya Nagarjuna University, India
}

\begin{abstract}
The postmodern phenomenon of globalization has launched digitalization as an outcome and the part of communication technologies by which the world has been brought together transcending the barriers of countries and cultures. The increase of global trade and the necessity of close and interlinked association among the nations at various stages of development have become imperative today as a historical necessity for future survival. Communication skills, especially in English, have become a crucial ingredient in all most all activities of life as communication channels are the arteries through which information flows and circulates to sustain any activity without disruption. Besides, to that the growth of coordination and collaborative activities in all spheres of life both public and private. Acquisition of and master over communication skills are the intellectual tools by which one's competence is measured and career is enhanced. In the age of specialization and hierarchal structures of large organizations, communication is the link connecting and synergizing all activities and ability to communicate clearly and effectively is of immeasurable significance, to assume an important place in any organization.

Every field of activity has its own specific vocabulary, specialized jargon and modes of communication which should be mastered by all participants to maintain the overall activity, especially in the age of digitalization. To rise effectively in one's career and contribute satisfactorily and successfully, special packages of communication skills should be designed and imparted to all potential candidates who are ambitious of to rise high in one's career. The inauguration of digital age made it both convenient to choose ones place and time for learning and also challenging as to how to utilize the recent technologies to enhance and extend ones communicative reach to become successful in one's career. The purpose of this paper is to discuss the various programs and strategies of communication necessary to enhance ones career prospects by training the participants to equip themselves with right competitive communication skills in tandem with contemporary digital technology available.
\end{abstract}

Keywords: Communication; Skills; Key; Career.

Cite This Article: Palle Manohar, and Dr.G. Chenna Reddy (2018). "COMMUNICATION SKILLS AS A KEY TO CAREER DEVELOPMENT IN THE DIGITAL AGE." International Journal of Research - Granthaalayah, 6(10), 227-231. 


\section{Introduction}

Digitalization is the process of converting information into a digital (computer-readable) format, in which the information is organized into bits. The result is the representation of an object, image, sounds, documents or signals by generating a series of numbers that describe a discrete set of its points or samples. Digitizing simply means the conversion of analog source material into a numerical format; the digit or any other number system that can be used. The term digitization is often used when diverse forms of information, such as an object, text, sound, image or voice etc. The advantage of digitization is the speed and accuracy in which this form of information can be transmitted with no degradation compared with analog information.

It is a well-known fact that Digital Age is the outcome of many innovations and technological advancements in the present Era. These transform the lives of people in many ways and will empower the society in a better manner than before. The motive behind the concept Digital Age is to build participative, transparent and responsible system. The main aim of this present generation is to remodel any nation into a knowledgeable economy and digitally empowered society. With the help of the technology it is possible good governance for citizens and co-ordination in public accountability, digitally connecting and delivering the government programs and services to mobilize the capability of information technology across government departments. Today, every nation wants to be totally digitalized and the technology strives to provide equal benefit to the user and service provider.

There is a possibility to the educational institutions and government services will soon be able to provide technology round the clock. Technology will provide all services electronically and promote digital literacy. Digital Technologies which includes the concept of mobile applications and cloud computing have emerged to express economic growth and citizen empowerment. Companies all over the world desire to invest on Digital Technology in the 21 st century. In this connection 'Digital India' programme has been initiated by honourable Prime Minister Mr. Narendra Modi, will emerge new progressions in every sector and generates innovative endeavours for next generation.

\section{Impact of Digitalization}

Digitalisation, which harnesses the power of connecting the people, process, data and things, will transform industries and change the way people work and how governments serve its citizens. A report by the Columbia University has identified that digitisation has a larger contribution to GDP to the present Economy of the nation. It states that a 10 point increase in digitisation yields a $0.74 \%$ increase in per capita GDP. There is a huge divide between rural and urban India and the digital haves and have-nots, digitisation will be key to maintaining India's global competitiveness, GDP growth, innovation and creating employment.

\section{Need for Programming Communication Skills}

Face Book: Mark Zukarberg and his friends founded the social media networking giant Facebook. It was launched on $4^{\text {th }}$ February 2004. Facebook is available in many languages but it helps user uses it in English. In the Facebook one can feel free to communicate in English because the language is not spoken verbally as there is no fear of getting caught with speaking grammatically 
wrong English. Facebook provides a lot of time. Then the user can read and take his own time to react. So that the user can get enough time to check his grammar and will be able to make necessary corrections. User can read the comments and also can read his own. This helps the user to user to use his English skills. Facebook acts like global world; it connects the people from different corners of the world. Making English friends will also be helpful in learning English. Posting updates in English and reacting to people of Facebook in English can make the user a better English-speaking person. There are many pages like learn English, voice of America, Dictionary.com, Practice English everyday etc., contribute to the English learning aspirants.

Twitter: Twitter is the trending social Website, one can share messages, meet new people, keep in touch with friends, promote products blogs and many more. All most all the conversations are public in twitter, so any one can join them. There is a limit of 140 characters in twitter. This limit, reading short sentences will be a great practice for reading skills. There are a few hash tags which are really helpful to the users, who are interested in learning English. Twinglish for English learning, Ell chat, TESOL and many more hash tags help the users in learning English.

YouTube: YouTube is an American video sharing website. Anyone can up lode all types of videos. One can find many videos on English speaking tutorials on the YouTube. It has flexibility that it has pause and play. It is not a boring class anymore. YouTube provides a wide variety of videos of which help in learning English speaking and accent. English speaking with Mr. Duncan, Reach English, and BBC learn English, British Council for kids, Business English POD are the famous channels among the English teaching channels. YouTube is the largest video portal and the second largest video search engine. It offers unlimited opportunities for formal and informal learner centered language learning approaches. Its videos can be used in digital classrooms for various aspects to enhance new vocabulary, accents, voice modulation, stress and intonation.

Whatsapp: Whatsapp created the new trend in communication, especially in learners life. It helps to interact with their friends as well as with the teachers who can clarify their doubts and also information among their friends can be shared easily. Today many apps like Whatsapp are coming to android market. A good response has been creating a tremendous market for these apps which tells the number of users is increasing day by day. Whatsapp offers many opportunities to express their ideas and feelings about the issues as well as to improve their English language skill.

E-Mail: E-mail is mainly is used for official purpose. It is the old and trusted mode of communication in internet. As it is used for official purposes people have to use good and the language, which can be easily understood by that officials. So, use of E-mails can definitely be helpful in enhancing the language skills.

Skype: Skype is used for different purposes. Many companies are conducting conferences through the Skype. The one who participates in conference must be very conscious with his language as many officials observe. It is a free internet telephone service. It promotes unlimited possibilities for the teachers and learners to teach and learn collaboratively anywhere in the world. Learners can enjoy face to face learning with native speakers. It has become an official platform for the teachers to be sold themselves for high salary as most of the interviews held in Skype. 
The Future Aspects: Technology has its positive impact on the education process. Educators also recognize the importance of developing these technological skills in students. As we sail through the $21^{\text {st }}$ century, technology in the classroom is becoming more and more predominant. The impact that technology has had on today's schools has been quite significant. This widespread adoption of technology has completely changed the way of teaching and learning methods. Teachers learn how to teach with emerging technologies (tablets, Smart Boards, Computers). At the same time students use advanced technology to shape how they learn. Students prefer technology because they believe that it makes learning more interesting and funny. They specially like laptaps and smart phones. Subjects that students deem challenging or boring may become more interesting with virtual lessons, through video or computer.

Technology trains students for the future. Technology, with its resources, in the classroom would help to prepare them for the digital future. These $21^{\text {st }}$ century skills are indispensable in order to be flourishing in this era. Technology assists students to learn at their pace. Today's technology enables students to learn at their own pace. For example, almost all apps allow for individualized instruction, students may learn according to their needs and abilities. This form of teaching and learning is also great both for the students and teachers because it saves time to work.

Digital infrastructure for every citizen of India, with an aim to drive the enablement of urban and rural digital infrastructure primarily to provide eGovernance and mGovernance to citizens.

Governance and service on demand, which will focus on driving the modernisation and reengineering of government processes and services to simplify governance.

Digital empowerment of citizens, with the goal to address the current gap of the digital "haves "and "have-nots "by developing skills and capacities.

\section{Conclusion}

The modern competitive world expects communicative skills and high English language proficiency as an essential element for all the students. English language learning has become a necessity for every Indian student today. Language learning is not the same as well as learning any other subject. Computer technology has made a necessary tool for learning and developing the skills of oral and written interactions, which is called as Computer Assisted Language Learning or Mobile Assisted Language Learning. This is the process of learner centric rather than teacher centric. This new way of language learning is fast gaining acceptance by all. It is the best advantage for non-native learners for whom English is a second language. Students from different cultures, regions and communities feel hard to learn English and its proficiency.

\section{References}

[1] Carver, D. Some Propositions about ESP. English for Specific Purposes, Cambridge: Cambridge University Press, 1983, pp.131-137.

[2] Gokak, V.K., English in India: It's Present and Future. Bombay: Asia Publishing House, 1964.

[3] Gita Nagaraj, English Language Teaching Approaches, Methods, Techniques, Oriented Longman Pvt. Ltd., Kolkata, 1996.

[4] Richard, J.C. The Context of Language Teaching. Cambridge: Cambridge University Press. 1985. 
[5] Tickoo, M.L Routledge Encyclopedia of Language Teaching and Language Learning, Michael Byram (ed), London: Routledge, 2000.

[6] https://www.linkedin.com/pulse/importance-communication-skills-students-communication.

[7] https://www.english.com/blog/technology-trends-in-english

[8] https://www.britishcouncil.org/voices-magazine/the-benefits-new-technology-language-learning

[9] https://www.english.com/blog/students-can-use-technology-improve-english

*Corresponding author.

E-mail address: manoharpalle22@ gmail.com 